\title{
ARTICLE
}

\section{Silicon oxycarbide glass-graphene composite paper electrode for long-cycle lithium-ion batteries}

\author{
Lamuel David', Romil Bhandavat ${ }^{1}$, Uriel Barrera ${ }^{1} \&$ Gurpreet Singh ${ }^{1}$
}

Silicon and graphene are promising anode materials for lithium-ion batteries because of their high theoretical capacity; however, low volumetric energy density, poor efficiency and instability in high loading electrodes limit their practical application. Here we report a large area (approximately $15 \mathrm{~cm} \times 2.5 \mathrm{~cm}$ ) self-standing anode material consisting of molecular precursor-derived silicon oxycarbide glass particles embedded in a chemically-modified reduced graphene oxide matrix. The porous reduced graphene oxide matrix serves as an effective electron conductor and current collector with a stable mechanical structure, and the amorphous silicon oxycarbide particles cycle lithium-ions with high Coulombic efficiency. The paper electrode (mass loading of $2 \mathrm{mg} \mathrm{cm}^{-2}$ ) delivers a charge capacity of $\sim 588 \mathrm{mAh}^{-1}$ electrode $\left(\sim 393 \mathrm{mAh} \mathrm{cm}^{-3}\right.$ electrode $)$ at 1,020th cycle and shows no evidence of mechanical failure. Elimination of inactive ingredients such as metal current collector and polymeric binder reduces the total electrode weight and may provide the means to produce efficient lightweight batteries.

\footnotetext{
${ }^{1}$ Mechanical and Nuclear Engineering Department, Kansas State University, 3002 Rathbone Hall, Kansas, Manhattan, Kansas 66506, USA. Correspondence and requests for materials should be addressed to G.S. (email: gurpreet@ksu.edu).
} 
C oncentrated efforts are currently employed to discover a practical replacement for traditional Li-ion battery electrodes that is, graphite anode and $\mathrm{LiCoO}_{2}$ cathode with materials that continuously deliver high power and energy densities at high cycling efficiencies without damage ${ }^{1-5}$. Alloying reaction electrodes such as silicon that can deliver as much as 5-10 times higher discharge capacity than traditional graphite, are at the forefront of this research. High capacity electrodes, however, are prone to enormous volume changes $(\sim 300 \%)$ that generally lead to structural collapse and capacity fading during successive lithiation/delithiation ${ }^{6-12}$. Recent work has shown that decreasing particle size or electrode nanostructuring allows the electrode to withstand high volumetric strains associated with repeated $\mathrm{Li}$ alloying and dealloying. Pomegranate-inspired carbon-coated Si nanoparticles, yoke shell-structured $\mathrm{SiC}$ nanocomposites and $\mathrm{Si} / \mathrm{C}$ core/shell composites (prepared at low mass loading) have proven to survive several hundred cycles without damage ${ }^{9-13}$. Yet, electrode nanostructuring has lead to new fundamental challenges such as low volumetric capacity (low tap density), increased electrical resistance between the nanoparticles, increased manufacturing costs and lower Coulombic efficiency due to side reactions with the electrolyte. These challenges have not been fully addressed. What's more, a particle-based electrode's long-term cyclability hinges on the inter-particle electrical connection and particle adhesion to the metallic substrate, which decreases rapidly with increasing charge/discharge cycles, particularly for thick high-loading electrodes 9 .

In this context, the graphene-based multicomponent composite anodes are an attractive alternative to traditional (binder and carbon-black) designs, chiefly because of graphene's superior electronic conductivity, mechanical strength and ability to be interfaced with $\mathrm{Li}$ active redox components, such as particles of $\mathrm{Si}, \mathrm{Ge}$, and transition metals sulfides/oxides resulting in electrodes that are intrinsically conducting and promote faster ion diffusion ${ }^{14-38}$. Additional advantages include weight savings of up to $10 \%$ of the total battery weight ${ }^{7}$, if the electrode is prepared in the freestanding form, improved corrosion resistance (elimination of metal foil), and enhanced flexibility, particularly for bendable, implantable, and roll-up electronics.

In spite of these advantages, graphene-paper electrodes do not offer an absolute solution because of the following associative disadvantages: (a) potential limiting of overall battery capacity due to insufficient active mass (thickness generally limited to submicrometers), (b) expensive techniques required for synthesis of Li-redox components and (c) more important, paper anodes generally show very high first cycle loss (50-60\%), low cycling efficiency (95-98\%) and poor capacity retention at high current densities (damage at high C-rates) ${ }^{23-39}$, making graphene-paper electrodes somewhat impractical for use in an Li-ion battery fullcell. Here again, very few studies have been performed to investigate the mechanical and fracture properties of composite paper-based electrodes.

Continued search for better anodes has brought attention to unique, rarely studied molecular precursor-derived Si-based glass-ceramics (such as silicon oxycarbide or SiOC and silicon carbonitride or SiCN) materials ${ }^{40-50}$. SiOC is a high-temperature glass-ceramic with an open polymer-like network structure consisting of two interpenetrating amorphous phases of SiOC ( $\mathrm{Si}$ bonded to $\mathrm{O}$ and $\mathrm{C}$ ) and disordered carbon ${ }^{42}$. Its low weight density $\left(\sim 2.1 \mathrm{~g} \mathrm{~cm}^{-3}\right)$ and open structure enables high charge and discharge rates with a gravimetric capacity more than twice that of commercial graphite electrode. More important, major portion of the electrochemical capacity in SiOC is due to reversible Li-adsorption in the disordered carbon phase and not the conventional alloying reaction with $\mathrm{Si}$, ensuing relatively lower volumetric changes ${ }^{43,44}$. Regrettably, the glass-ceramics that show high lithiation capacity are poor conductors of electronic/ionic current and consequently the electrode preparation involves incorporation of conducting agents and binders in order to hold the particles on a metal current collector, a method known as screen printing ${ }^{45-47}$. Such foil-based electrodes carry the dead weight of conducting agents, polymeric binders, and the metal foil that do not contribute towards the battery capacity.

As an attractive solution to screen printed electrodes, we present our results related to fabrication of a well-organized, interleaved, freestanding, large-area composite anode consisting of SiOC particles supported by crumpled reduced graphene oxide matrix. The electrode delivers higher volumetric capacity than the recently reported pomegranate $\mathrm{Si} /$ carbon nanotube $\left(310 \mathrm{mAh} \mathrm{cm}^{-3}\right)$ paper-electrode ${ }^{9}$. Large micrometer size reduced graphene oxide ( $\mathrm{rGO}$ ) sheets serve as host material to SiOC particles, providing the necessary electronic path and consistent cycling performance at high current densities along with high structural stability. Because of their unique nanodomain amorphous structure, SiOC particles offer required chemical and thermodynamic stability and high Li intercalation capacity for the electrode. As a result the electrode (at least $2 \mathrm{mg} \mathrm{cm}^{-2}$ weight loading) has first cycle charge capacity of $702 \mathrm{mAh} \mathrm{g}^{-1}$ electrode (total weight of electrode considered) and $\sim 470 \mathrm{mAh} \mathrm{cm}^{-3}$ electrode (total volume of electrode considered) at $100 \mathrm{mAg}^{-1}$ electrode and stable charge capacity of $543 \mathrm{mAh} \mathrm{g}^{-1}$ electrode $\left(\sim 363 \mathrm{mAh} \mathrm{cm}^{-3}\right.$ electrode $)$ at charge current density of $2,400 \mathrm{mAg}^{-1}$ electrode. The capacity is $\sim 200 \mathrm{mAhg}^{-1}$ electrode when cycled at $\sim-15^{\circ} \mathrm{C}$. Further, the composite electrode has exceptionally high strain-to-failure (exceeds 2\%) as measured in a uniaxial tensile test and the mode of failure differ significantly from pristine rGO papers.

\section{Results}

Material synthesis and electrode fabrication. Polymer-derived SiOC ceramic particles were prepared by controlled thermolysis of 1,3,5,7-tetramethyl-1,3,5,7-tetravinylcyclotetrasiloxane (TTCS) polymeric precursor while graphene oxide $(\mathrm{GO})$ was prepared by the modified Hummer's method ${ }^{51}$ (for details, see Methods section). The polymer-to-ceramic transformation was complete at $1,000{ }^{\circ} \mathrm{C}^{41}$. Detailed characterization of cross-linked polymer and resulting SiOC material is presented in Fig. 1a-g. SEM images of SiOC particles in Fig. 1a confirmed average particle size to be $\sim 4 \mu \mathrm{m}$ (with s.d. $=1.8 \mu \mathrm{m}$ ). X-ray photoelectron spectroscopy (XPS) showed $\mathrm{O} 1 s, \mathrm{C} 1 s, \mathrm{Si} 2 s$, Si $2 p$ and $\mathrm{O} 2 s$ peaks for both cross-linked and pyrolyzed SiOC ceramic (Fig. 1b). Close analysis of the deconvoluted silicon band (for Si $2 p$ photoelectrons) in $\mathrm{SiOC}$ revealed the emergence of peaks at 103.5 and $102.2 \mathrm{eV}$, corresponding to $\mathrm{SiO}_{4}$ and $\mathrm{CSiO}_{3}$ phases, respectively (Fig. 1c). In addition, peaks at $534.5,533.1$ and $532.4 \mathrm{eV}$ corresponding to $\mathrm{C}=\mathrm{O}, \mathrm{SiO}_{2}$ and $\mathrm{Si}-\mathrm{O}$ phases, respectively, were observed in $\mathrm{O} 1 \mathrm{~s}$ band (Fig. 1d), whereas the $\mathrm{C} 1 \mathrm{~s}$ band (Fig. 1e) was fitted with 3 peaks at $286.5,284.5$ and $284.7 \mathrm{eV}$ corresponding to $\mathrm{C}=\mathrm{O}, \mathrm{C}-\mathrm{C}$ and $\mathrm{C}-\mathrm{Si}$ phases, respectively. Surface elemental composition from XPS was measured to be $\mathrm{C}=62.55$ at $\%$ (50.35 wt\%), $\mathrm{O}=25.73$ at $\%(27.57 \mathrm{wt} \%)$ and $\mathrm{Si}=11.72 \mathrm{at} \%$ (22.06 wt $\%)$. XPS composition after $80 \mathrm{~min}$ of depth profiling (with $5 \mathrm{keV}$ Ar-ion) showed lower carbon and oxygen content of 50.78 at $\%$ $(34.47 \mathrm{wt} \%)$ and $18.44 \mathrm{at} \% \quad(16.66 \mathrm{wt} \%)$, respectively with $\mathrm{Si}$ at 30.78 at\% (48.85 wt\%) (see Supplementary Fig. 1). Bulk composition of SiOC particles was also determined from combustion and inert gas fusion techniques (see Supplementary Fig. 2a,b and Methods section for details). The composition was found to be $\mathrm{C}=51.24$ at\% (38.3 wt\%), $\mathrm{O}=19.79 \mathrm{at} \%$ (19.7 wt\%), 
a

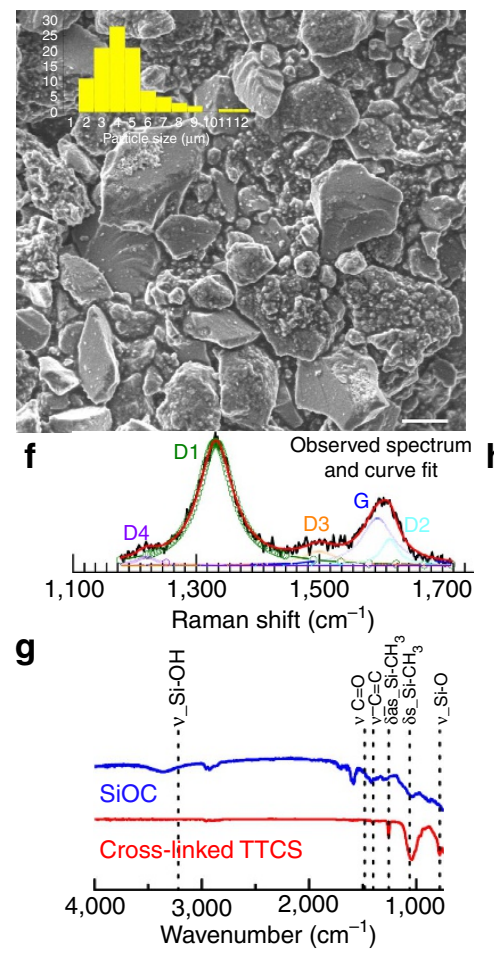

b

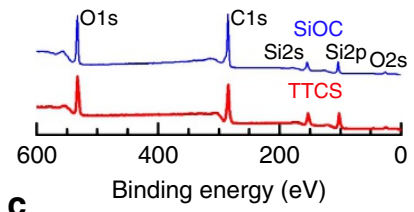

C

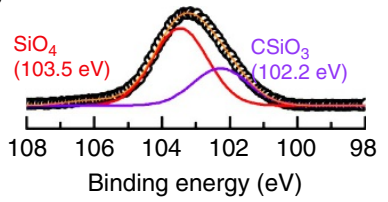

d

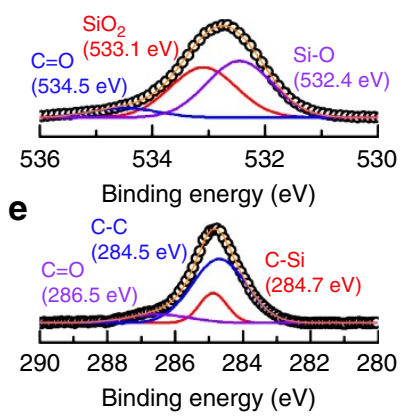

$\mathbf{h}$
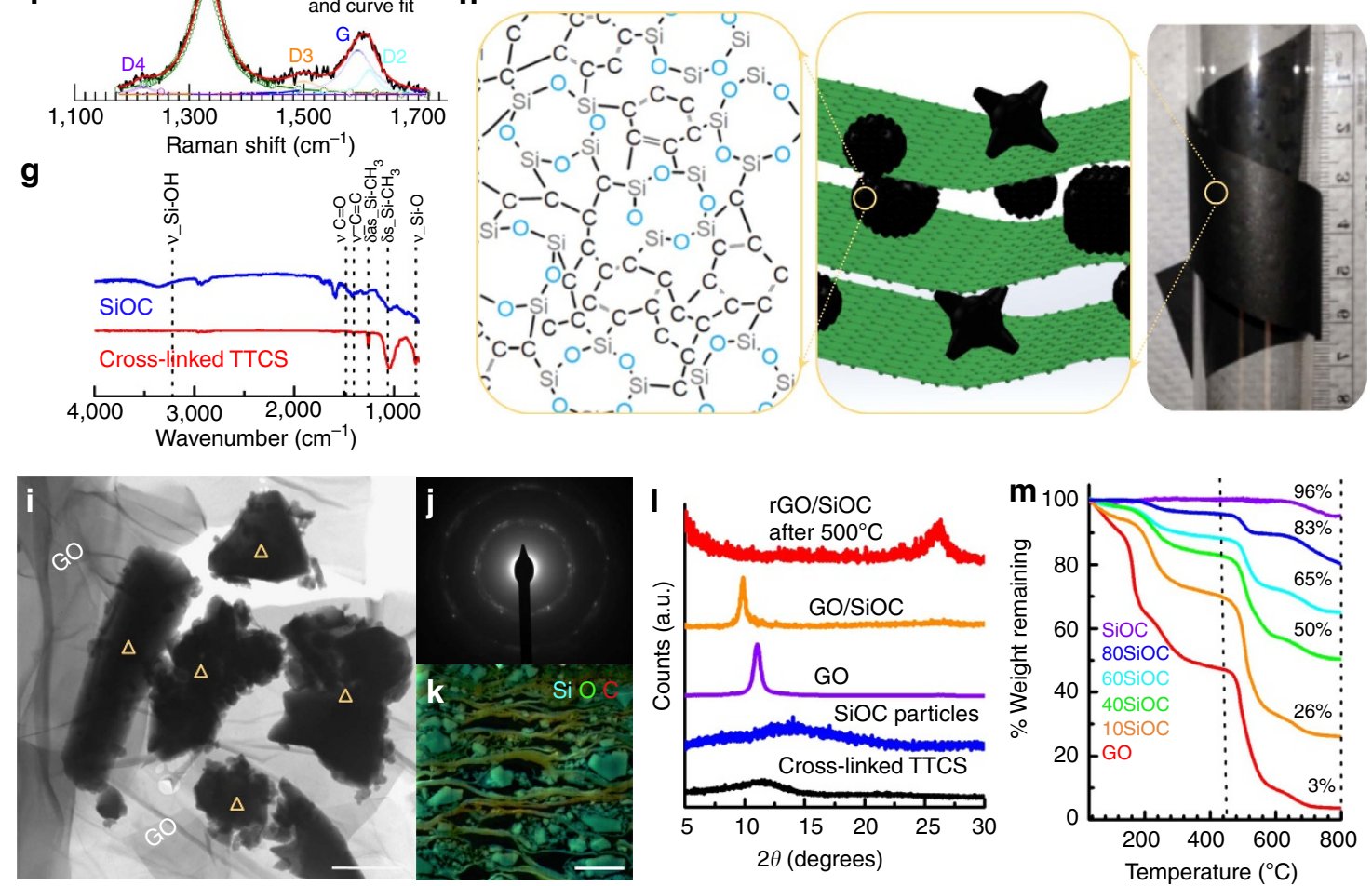

Figure 1 | Characterization of SiOC ceramic and SiOC/graphene composite papers. (a) SEM image of SiOC particles after pyrolysis of the polymeric TTCS particles. Sharp glass-like particles decorated with sub-micron size particles were observed. Scale bar is $5 \mu \mathrm{m}$. (b) XPS survey scans for cross-linked TTCS and pyrolyzed SiOC. High resolution XPS spectrum of pyrolyzed SiOC particles in the (c) Si $2 p$ region, (d) O $1 s$ region and (e) C $1 s$ region were consistent with the polymer-derived $\mathrm{SiOC}$ nanodomain model. Deconvoluted peaks indicate the various bonds between $\mathrm{Si}, \mathrm{C}$ and $\mathrm{O}$ atoms that are distinct to pyrolyzed SiOC. (f) Raman spectrum of SiOC showed peaks that are characteristic of graphite-like carbon (D1-peak: 1,350 cm ${ }^{-1}$ and G-peak: $1,590 \mathrm{~cm}^{-1}$ ). (g) Fourier Transform Infrared Spectroscopy spectra of SiOC and cross-linked TTCS ( $v$ : stretching vibration mode and $\delta$ : bending vibration mode). (h) Digital camera picture and schematic illustration of proposed hybrid structure of the freestanding paper along with the atomic structure of pyrolyzed SiOC particle. (i) TEM image of SiOC/GO composite material. Large GO flakes covering SiOC particles $(\Delta)$ were observed. Scale bar is $500 \mathrm{~nm}$. (j) Corresponding TEM selected area electron diffraction pattern showed multiple spot pattern due to polycrystallinity of restacked $\mathrm{GO}$ sheets with faint ring pattern attributed to amorphous $\mathrm{SiOC}$ material. (k) FIB cross-sectional EDX elemental map of $60 \mathrm{SiOC}$ paper in which $\mathrm{Si}, \mathrm{C}$ and $\mathrm{O}$ are indicated by blue, red and green, respectively. The scale bar is $5 \mu \mathrm{m}$. Additional TEM and SEM images are presented in Supplementary Figs. 6-8. (I) XRD of cross-linked TTCS, SiOC particles, GO and composite papers before and after thermal reduction (annealing). Complete reduction of GO to rGO is illustrated in the plot. (m) TGA curves of GO paper and unannealed composite paper measured from 30 to $800^{\circ} \mathrm{C}\left(10^{\circ} \mathrm{C} \mathrm{min}^{-1}\right)$ in flowing air $\left(20 \mathrm{ml} \mathrm{min}{ }^{-1}\right)$. The weight percentage of $\mathrm{SiOC}$ in the unannealed composite is as indicated in the figure.

$\mathrm{H}=5.09$ at $\% \quad(0.31 \mathrm{wt} \%) \quad$ and $\quad \mathrm{Si}=23.85$ at $\% \quad(41.68 \mathrm{wt} \%)$. The elemental composition obtained from various techniques is summarized in Supplementary Table 1. Raman spectroscopy of $\mathrm{SiOC}$ particles was performed to further confirm the existence of the free or excess carbon domains. As shown in Fig. 1f, five peaks could be fitted into the spectrum: D1 or D-band $\left(\sim 1,330 \mathrm{~cm}^{-1}\right)$, D2 $\left(\sim 1,615 \mathrm{~cm}^{-1}\right), \mathrm{D} 3\left(\sim 1,500 \mathrm{~cm}^{-1}\right), \mathrm{D} 4\left(\sim 1,220 \mathrm{~cm}^{-1}\right)$ and the G-band $\left(\sim 1,590 \mathrm{~cm}^{-1}\right)^{52}$. D1, D2 and D4 originate from disordered graphitic lattice (graphene layer edges, surface layers and polyenes and so on) while D3 is associated with amorphous carbon soot. G-band corresponds to the ideal graphitic lattice. In addition, two bumps centered at $\sim 2,640\left(2{ }^{*} \mathrm{D}\right.$ overtone) and $\sim 2,915 \mathrm{~cm}^{-1}$ (D+G combination) were also observed (Supplementary Fig. 3). Similarly, Fourier Transform Infrared Spectroscopy (FTIR) analysis also confirmed transformation of TTCS polymer to ceramic SiOC (Fig. 1g) ${ }^{41}$. Based on spectroscopic evidence, the predicted chemical structure of the cross-linked polymer and resultant ceramic is presented in Supplementary Fig. 4, which is in agreement with previous work on polymer-derived $\mathrm{SiOC}^{42}$. 
The composite papers were prepared following a vacuum filtration technique (see Materials section for details and schematic in Supplementary Fig. 5). Samples were labeled as rGO, 10SiOC, 40SiOC, 60SiOC and 80SiOC for rGO paper and GO with $10,40,60$ and $80 \mathrm{wt} \%$ of SiOC in the paper, respectively. The digital camera image and schematic in Fig. $1 \mathrm{~h}$ highlights the flexibility and structure of the composite paper, respectively.

Morphology of the composite and thermally reduced (annealed) freestanding papers was studied by electron and focused ion beam (FIB) microscopy. The transmission electron microscope (TEM) image (Fig. 1i) showed large micrometer-sized thin GO sheets along with random shape glass-like SiOC particles (also see Supplementary Fig. 6a-e). Large SiOC particles were seen to be covered with smaller nanometer size particles. The graphene platelets seem to ocassionaly fold and cover individual SiOC particles and other instances show GO being interlayered by SiOC. EDX elemental mapping performed in scanning-TEM mode (Supplementary Figs. 6a-e) confirmed the uniform distribution of $\mathrm{Si}, \mathrm{O}, \mathrm{C}$ in the particles with higher concentration of $\mathrm{C}$ observed near the edges possibly due to graphene platelets. For the selected area electron diffraction pattern in Fig. 1j, the multiple spot pattern is a result of polycrystallinity of restacked GO sheets and the faint ring pattern is attributed to amorphous SiOC material. The SEM images of the freestanding papers showed a sheet-like structure with a relatively smooth top surface for rGO paper ${ }^{53-56}$, which became increasingly rough and porous with higher loading of SiOC particles in the composite (Supplementary Fig. 7a-d). Cross-sectional SEM of the fractured samples revealed ordered stacks of $\mathrm{rGO}$ with SiOC particles interlayered between the sheets (Supplementary Fig. 7e-h). Several micrometer sized particles could be seen for 60SiOC specimen along with clumped nanometer sized particles. Nonetheless, mechanically fractured composite papers were largely uneven and showed signs of damage to the interface. To obtain a smooth and defect-free cross-section, the 60SiOC paper was sectioned by means of a FIB milling (see Methods section and Supplementary Fig. 8a for details regarding specimen preparation). The uniform distribution of SiOC particles and wrapping by large-area graphene platelets could be clearly observed in the electron beam (Supplementary Fig. 8b) and ion-beam images (Supplementary Fig. 8c). Elemental mapping by means of EDX (Fig. 1k and Supplementary Fig. 8d-f) further established the inter-layered morphology of the composite. Depending up on the SiOC content, the average thickness of the papers varied between $\sim 20$ and $30 \mu \mathrm{m}$.

The reduction of GO (non-conducting) to $\mathrm{rGO}$ (conducting) was confirmed by use of X-ray diffraction (XRD). As shown in Fig. 1l, both GO and unannealed composite papers, had peaks at 11.05 and $9.8^{\circ}$, corresponding to interlayer spacing of 8 and $12 \AA$, respectively. Interlayer spacing was large compared with that of graphite (with major peak (002) at $26.53^{\circ}$, corresponding to $3.36 \AA$ ) because of oxygen functional groups present in GO and water molecules held between the layers. After thermal annealing at $500^{\circ} \mathrm{C}$ for $2 \mathrm{~h}$, the paper showed a broad peak at $2 \theta=26^{\circ}$, typical of reduced GO material ${ }^{55,56}$. The broad peak observed in the spectra suggests inhomogeneous spacing between the layers. XRD spectra of cross-linked TTCS and SiOC particles were both featureless, confirming the amorphous nature of these ceramics (hallmark of these materials). Raman spectrum $\left(I_{d} / I_{g}\right)$ pre and post thermal reduction showed a slight change in accordance with previous reports (Supplementary Fig. 9) ${ }^{39}$. Reduction of GO to rGO was verified by the disappearance of oxide peaks in the high resolution XPS analysis of C $1 s$ peak (Supplementary Fig. 10).

Thermogravimetric analysis (TGA) was performed to ascertain the mass loading of $\mathrm{SiOC}$ in the composite papers. Figure $1 \mathrm{~m}$ shows the percentage composition of filtered composite paper prior to their thermal reduction. Significant weight loss was observed in the $50-100^{\circ} \mathrm{C}$ and $100-400^{\circ} \mathrm{C}$ temperature ranges, which is attributed to evaporation of trapped water molecules in the GO and oxygen functionalities, respectively ${ }^{57-59}$. The weight loss was highest for GO and lowest for $80 \mathrm{SiOC}$ (see Supplementary Table 2). Final weight loss in the $400-800^{\circ} \mathrm{C}$ range is due to burning of carbon material. Comparatively, the initial weight loss was not observed in thermally reduced samples (mere $1.2 \%$ for $\mathrm{rGO}$ at $400{ }^{\circ} \mathrm{C}$, Supplementary Fig. 11) that suggests high degree of water removal and oxygen groups by thermal annealing. Approximately $3 \%$ and $6-10 \%$ residue was noted for GO and rGO material at $\sim 800^{\circ} \mathrm{C}$. As a result SiOC content (or percentage weight remaining) in the thermally reduced composite was higher than unannealed specimens; SiOC content in $10 \mathrm{SiOC}, 40 \mathrm{SiOC}, 60 \mathrm{SiOC}$ and $80 \mathrm{SiOC}$ increased from $\sim 10-30 \%, \sim 50-65 \%, \sim 65-78 \%$ and $\sim 83-92 \%$, respectively. In the traditional method of electrode preparation, active material (including recently reported graphene embedded PDC material) is mixed with polymeric binder and conductive agent in an $\sim 80: 10: 10$ ratio, followed by slurry coating on metal current collector foil ${ }^{47}$. However, using the present method we have made a freestanding and lightweight electrode, containing up to $\sim 78 \%$ SiOC as active material and $\sim 22 \%$ of rGO (acting as binder and conductive agent). Paper electrodes were directly utilized as the working electrodes. Electrochemical performance is presented in the following section.

Electrochemical performance. Figure 2a shows charge capacities and columbic efficiency of $\mathrm{rGO}, 10 \mathrm{SiOC}, 40 \mathrm{SiOC}, 60 \mathrm{SiOC}$ electrodes asymmetrically cycled at varying charge current densities. For rGO, the first-cycle charge capacity at $100 \mathrm{mAg}^{-1}$ electrode was $\sim 210 \mathrm{mAhg}^{-1}$ electrode, it dropped to $\sim 200 \mathrm{mAh} \mathrm{g}^{-1}$ electrode in the second cycle, and then the charge capacity stabilized at $\sim 180 \mathrm{mAhg}^{-1}$ electrode after five cycles. When charge current density increased to $2,400 \mathrm{mAg}^{-1}$ electrode, charge capacity was retained at $\sim 175 \mathrm{mAh} \mathrm{g}^{-1}$ electrode. Returning the current density back to $100 \mathrm{mAg}^{-1}$ electrode led to the return of higher capacity of $192 \mathrm{mAh} \mathrm{g}^{-1}$ electrode. High irreversible first-cycle capacity results from electrochemical reaction contributed to solid-electrolyte interphase (SEI) layer formation. For the composite electrode, the first-cycle charge capacity increased in correspondence to the percentage of SiOC in the electrode. For example, 10SiOC showed $376 \mathrm{mAh} \mathrm{g}^{-1}$ electrode, while $40 \mathrm{SiOC}$ and $60 \mathrm{SiOC}$ showed $546 \mathrm{mAh}^{-1}$ electrode and $702 \mathrm{mAh} \mathrm{g}^{-1}$ electrode (volumetric capacity of $\sim 470 \mathrm{mAh}$ $\mathrm{cm}^{-3}$ electrode), respectively. The 60SiOC capacity was lower than the capacity calculation based on a 'rule of mixture' approach $\left(\sim 793 \mathrm{mAhg}^{-1}\right)$ with constituent rGO (first cycle reversible capacity $\sim 210 \mathrm{mAh}^{-1}$ ) at $\sim 22 \mathrm{wt} \%$ as lower bound and SiOC (highest first cycle reversible capacity $\sim 958 \mathrm{mAhg}^{-1}$ from ref. 46) at $\sim 78 \mathrm{wt} \%$ as upper bound. Similar to rGO electrode, when charge current density increased to $2,400 \mathrm{mAg}^{-1}$ electrode, composites 10SiOC, 40SiOC and 60SiOC showed high reversible capacity at 296, 417 and $543 \mathrm{mAhg}^{-1}$ electrode, respectively. Capacity retention at $2,400 \mathrm{mAg}^{-1}$ electrode of $83.5 \%$ (compared with cycle number 5 at $100 \mathrm{mAg}^{-1}$ electrode) and first-cycle efficiency of $68 \%$ for $60 \mathrm{SiOC}$ is among the highest reported performances for a freestanding graphenebased electrode (see Supplementary Table 3 and Supplementary Table 4 for summary and comparison, respectively) ${ }^{14-19,23,25,32,38}$. When charge current density was lowered again to $100 \mathrm{mAg}^{-1}$ electrode at cycle number 31 , charge capacity increased to stable values of $304 \mathrm{mAhg}^{-1}$ electrode ( $\sim 80 \%$ retained $), 471 \mathrm{mAhg}^{-1}$ electrode $(\sim 96 \%$ retained $)$ and 
a

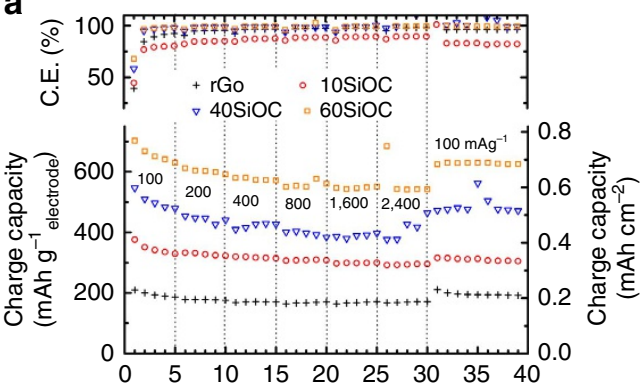

b
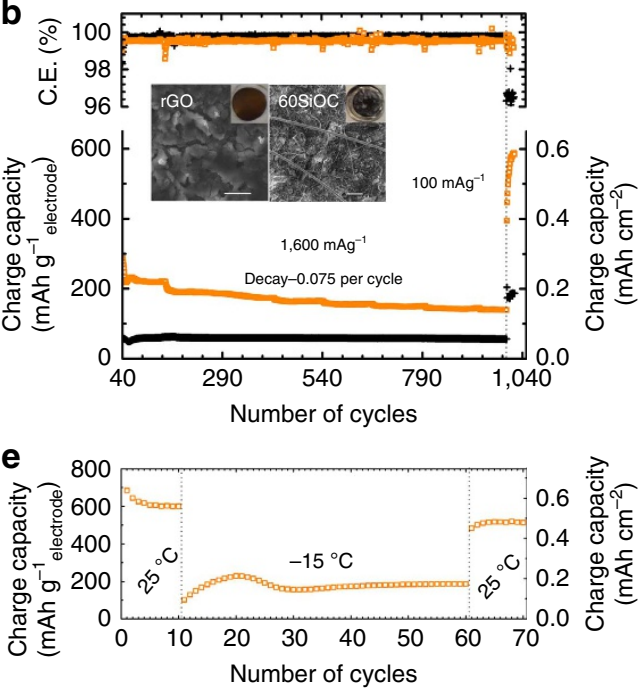

c

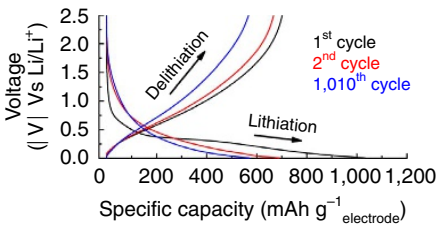

d

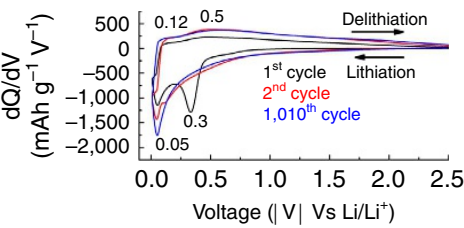

f
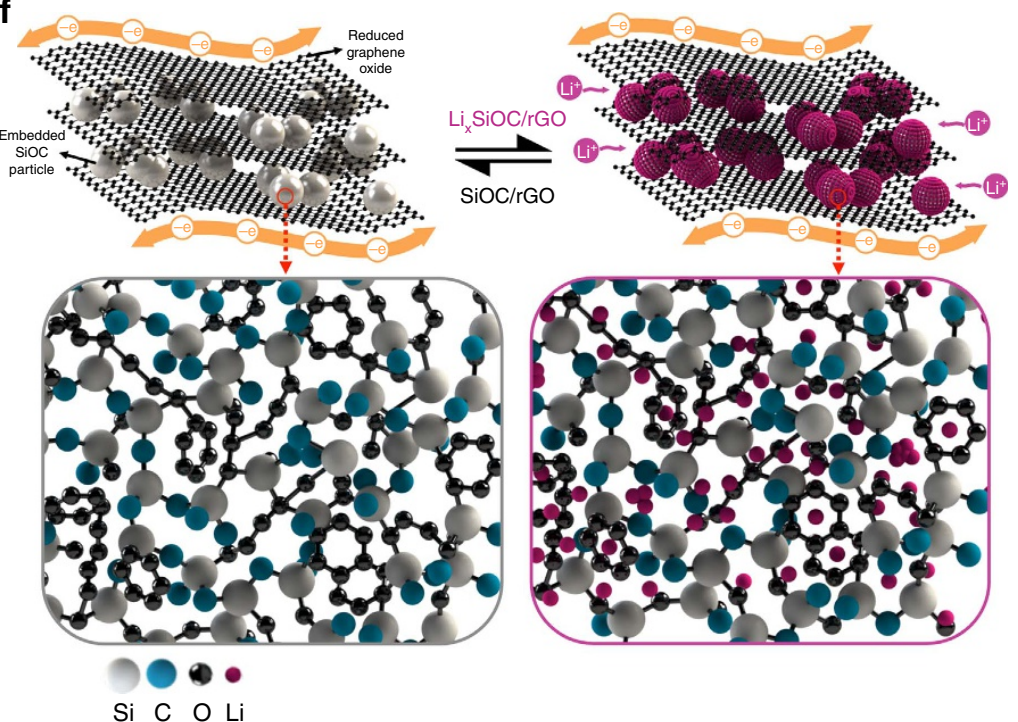

Si C O Li

Figure 2 | Electrochemical characteristics and proposed lithium storage mechanism. (a) Charge capacity and cycling efficiency of various paper electrodes when cycled asymmetrically at increasing charge current densities. (b) Extended cycling behavior of rGO and 60SiOC electrodes cycled symmetrically at $1,600 \mathrm{mAg}^{-1}$ electrode. After 970 cycles, the electrodes showed good recovery when the current density was lowered back to $100 \mathrm{mAg}^{-1}$ electrode. Insets show the post-cycling digital and SEM images of the dissembled rGO and 60SiOC electrodes. Scale bar is $10 \mu \mathrm{m}$. (c) Voltage profile of $60 \mathrm{SiOC}$ electrode and corresponding (d) differential capacity curves for 1st, 2nd and 1,010th cycle. (e) Cycling behavior of 60SiOC at sub-zero temperature. After cooling down to $\sim-15^{\circ} \mathrm{C}$, the cell demonstrated a stable charge capacity of $\sim 200 \mathrm{mAhg}^{-1}$ electrode at $100 \mathrm{mAg} \mathrm{g}^{-1}$ electrode. The cell regained $\sim 86 \%$ of its initial capacity when returned to cycling at room temperature $\left(\sim 25^{\circ} \mathrm{C}\right)$. (f) Schematic representing the mechanism of lithiation/ delithiation in $\mathrm{SiOC}$ particles. Majority of lithiation occurs via adsorption at disordered carbon phase, which is uniformly distributed in the SiOC amorphous matrix. Large rGO sheets serve as an efficient electron conductor and elastic support.

$626 \mathrm{mAhg}^{-1}$ electrode $(\sim 97 \%$ retained $)$ for 10SiOC, 40SiOC and $60 \mathrm{SiOC}$, respectively.

In order to test cyclic stability of the electrodes, the same cells were subjected to symmetric cycling at a current density of $1,600 \mathrm{~mA} \mathrm{~g}^{-1}$ electrode. Charge capacity for this test is shown in Fig. 2b. Charge capacity of 60SiOC showed some decline as the cells were subjected to prolong symmetric cycling at $1,600 \mathrm{~mA} \mathrm{~g}^{-1}$ electrode. The capacity decay over the 970 -cycle range was observed to be approximately $0.075 \mathrm{mAh} \mathrm{g}^{-1}$ electrode per cycle. This decline was not observed in the rGO specimen, thereby demonstrating the importance of graphene in the composite material. Nonetheless, the average composite paper capacity in this range was approximately three times higher than pristine rGO electrode $\left(\sim 170\right.$ versus $\sim 58 \mathrm{mAhg}^{-1}$ electrode). Most significantly, the cell capacities were $\sim 185(\mathrm{rGO})$ and $568 \mathrm{mAh} \mathrm{g}^{-1}$ electrode $(60 \mathrm{SiOC})$ at 1,010 th cycle when the current density was brought back to $100 \mathrm{~mA} \mathrm{~g}^{-1}$ electrode and stabilized to 186 and $588 \mathrm{mAh} \mathrm{g}^{-1}$ electrode, respectively at 1,020 th cycle before the tests were stopped for post-cycling analysis. This represents $\sim 94 \%$ capacity retention for 60SiOC when compared with capacity value at the 40th cycle prior to beginning of the longterm cycling test (see Supplementary Table 3). No measureable change in cycling efficiency of 60SiOC $(\sim 99.6 \%)$ was observed during this period. This shows that, even after 1,020 cycles, the composite electrode was robust and continued to function without appreciable degradation.

Supplementary Fig. 12a shows voltage profiles of rGO for the 1 st, 2nd and 1,010th cycle. Differential capacity profiles in Supplementary Fig. 12b were similar to previous reports on rGO electrodes, with a primary reduction peak at $\sim 50 \mathrm{mV}$, a secondary reduction peak at $\sim(520-560) \mathrm{mV}$, and an oxidation peak at $\sim(120-130) \mathrm{mV}^{39}$. The peak at $\sim 50 \mathrm{mV}$, present in all subsequent cycles, is associated with lithiation of graphitic carbon, whereas the peak at $\sim 560 \mathrm{mV}$ signifies formation of SEI, which exists only in the first cycle. Supplementary Fig. 12c and $\mathrm{d}$ show the voltage profile and differential capacity curves of 1 st and 2 nd cycle of $10 \mathrm{SiOC}$, respectively. The first cycle contained three reduction peaks at around $\sim 50, \sim 240$ and $\sim 520 \mathrm{mV}$, attributed to rGO lithiation, irreversible $\mathrm{Li}_{x} \mathrm{SiOC}$ formation, and SEI formation, respectively $39,41,45$. In contrast, only one subtle extraction peak at $\sim 110 \mathrm{mV}$ is observed, which represents rGO de-lithiation with an extended bulge at $\sim 500 \mathrm{mV}$ that represents $\mathrm{Li}_{x} \mathrm{SiOC}$ de-lithiation ${ }^{38,45-47}$. As the SiOC content increased to $40 \%$ (Supplementary Fig. 12e,f) and $60 \%$ (see Fig. 2c,d), domination of SiOC lithiation increased, as proven by increased intensity of the irreversible $\mathrm{Li}_{x} \mathrm{SiOC}$ formation peak at $\sim(270-300) \mathrm{mV}$. Peak intensity of $\mathrm{rGO}$ de-lithiation at $\sim 120 \mathrm{mV}$ diminished with respect to $\mathrm{Li}_{x} \mathrm{SiOC}$ 
de-lithiation bulge at $\sim 500 \mathrm{mV}$. In addition, the 2 nd and the 1,010 th cycle charge/discharge and differential capacity curves of the electrodes had similar profiles, showing that no new phases formed even after more than 1,000 cycles. More importantly, the efficiency of $60 \mathrm{SiOC}$ remained high throughout the cycling test.

Additional rate capability test involving extreme symmetric cycling were performed on freshly prepared 60SiOC paper electrode with even higher mass loading (approximately $3 \mathrm{mg} \mathrm{cm}^{-2}$ ). The data is presented in Supplementary Fig. 13 . Stable capacity of $\sim 700 \mathrm{mAhg}^{-1}$ electrode was observed at $100 \mathrm{mAg}^{-1}$ electrode which decreased to $\sim 100 \mathrm{mAhg}^{-1}$ electrode at $2,400 \mathrm{~mA} \mathrm{~g}^{-1}$ electrode and showed complete recovery when the current density was brought back to $100 \mathrm{mAg}^{-1}$ electrode. Such stable performance is rarely reported for precursor-derived ceramic materials even on traditionally prepared electrode on copper foil where the current density and capacity are reported with respect to the active material only ${ }^{46-48}$. Tests were also conducted on $80 \mathrm{SiOC}$ specimen to ascertain if the charge capacity of the freestanding paper-based electrodes can be improved even further due to higher SiOC content. These attempts, however, were not successful because electrodes prepared at $80 \%$ SiOC loading were brittle and showed erratic behavior after only a few initial cycles. First-cycle charge capacity for $80 \mathrm{SiOC}$ was $\sim 762 \mathrm{mAh} \mathrm{g}^{-1}$ electrode and showed domination of $\mathrm{Li}_{x} \mathrm{SiOC}$ lithiation $(\sim 330 \mathrm{mV})$ and delithiation $(\sim 500 \mathrm{mV})$ over rGO peaks, similar to other composite electrodes (Supplementary Fig. 14a,b). The 80SiOC electrode began to demonstrate random spikes in charge capacity and efficiency with increased cycle number at high C-rate possibly due to mechanical disintegration and loss of electrical contact due to insufficient rGO loading (Supplementary Fig. 15a). Crack could be observed in the post-cycling SEM images (see Supplementary Fig. 15b-e).

Four-point electrical conductivity measurements were performed and compared for all specimens (for details, see Supplementary Note 1 and Supplementary Fig. 16). Data is summarized in Supplementary Table 5. Although average four-point resistance for $60 \mathrm{SiOC}(580 \Omega)$ was higher than $\mathrm{rGO}$ paper $(40 \Omega)$, it still represents an important achievement because TTCS derived SiOC (under present pyrolysis conditions and for the given composition) was observed to be poor electrical conductor and the improved conductivity of the composite paper $\left(5 \times 10^{-2} \mathrm{Scm}^{-1}\right.$ versus $\sim 10^{-12} \mathrm{~S} \mathrm{~cm}^{-1}$ for SiOC powder $\left.{ }^{41}\right)$ is key to better $\mathrm{C}-$ rate characteristics. This is more evident when we compare the $\mathrm{C}$ - rate data for SiOC particle electrode prepared on traditional copper current collectors ${ }^{46}$, where the electrochemical capacity was observed to be near zero for cycling current density of $1,600 \mathrm{mAg}^{-1}$.

In addition to room temperature testing, the best performing specimen (that is, 60SiOC) was subjected to electrochemical cycling at sub-zero temperature at $\sim-15^{\circ} \mathrm{C}$ (for details, see Supplementary Note 2 ). When initially cycled at room temperature (Fig. 2e), the cell had a stable charge capacity of $\sim 600 \mathrm{mAh} \mathrm{g}^{-1}$ electrode that then reduced to a stable charge capacity of $\sim 200 \mathrm{mAhg}^{-1}$ electrode when cycled at low temperature. The cell regained $\sim 86 \%$ of its initial capacity when it returned to cycling at room temperature.

In order to verify electrode integrity, the cells were dissembled in their lithiated state and the electrode was recovered for additional characterization. The inset in Fig. $2 b$ and Supplementary Fig. 17 show the digital photograph and SEM image of the cycled electrodes. Post-cycling Raman spectroscopy data is presented in Supplementary Fig. 18 and Supplementary Table 6. No evidence of surface cracks, volume change, or physical imperfections were observed in the SEM images, suggesting high mechanical/structural strength of the composite paper towards continuous Li-cycling which could be attributed to unique structure of the electrode as shown in Fig. $2 \mathrm{f}$. In all cases, evidence of SEI formation due to repeated cycling of Li-ions was observed. Contamination in the specimen, indicated by arrows, was a result of residue of glass separator fibers. The electrodes were briefly exposed to air during the transfer process, resulting in oxidation of $\mathrm{Li}$, which appeared as bright spots in the images due to non-conducting nature.

To illustrate the kinetics of charge/discharge of the composite paper, Galvanostatic intermittent titration cycling was performed for the $60 \mathrm{SiOC}$ electrode at room and low temperature (for details, see Supplementary Note 3 ). Acquired $\mathrm{D}_{\mathrm{Li}+}$ varied between $\sim 10^{-14}$ and $\sim 10^{-15} \mathrm{~m}^{2} \mathrm{~s}^{-1}$ during insertion and extraction (Supplementary Fig. 19). These values are comparable with values reported for polymer-derived SiOC (Kasper et al. $10^{-13}$ to $\left.10^{-15} \mathrm{~m}^{2} \mathrm{~s}^{-1}\right)^{44}$. In addition, total polarization potential and time dependent change in open-circuit voltage (OCV) at various states of charge were inferred for these experiments, as shown in Supplementary Fig. 20a-d. Reaction resistance to $\mathrm{Li}$ insertion and extraction from the 60SiOC electrode was calculated by taking a ratio of OCV to the current density (Supplementary Fig. 20e,f). Reaction resistance was fairly constant at $2 \mathrm{Ohm} g$ during room temperature insertion. However, it increased exponentially to $8 \mathrm{Ohmg}$ during $\mathrm{Li}$ extraction in the $1.5-2.0 \mathrm{~V}$ range, which highlights the difficulty in extracting the very last $\mathrm{Li}$ atoms from amorphous SiOC structure (Fig. 2f). Density of state calculations (Supplementary Fig. 21) show that Li is stored at several energy levels in the amorphous SiOC structure, with majority of the insertion occurring in the $0-0.5 \mathrm{~V}$ range. Further, a voltage hysteresis of $\sim 0.5 \mathrm{~V}$ exists during the extraction half, which could be attributed to the hydrogen ( $\mathrm{H}$-terminated edges of free carbon phase) that are generally present in the SiOC derived from thermal decomposition of organosilicon polymers. $\mathrm{H}$ content in pyrolyzed ceramic particles was measured to be $\sim 0.25-0.3 \mathrm{wt} \%$ (for details, see Methods section, Supplementary Fig. 2, Supplementary Table 1). Galvanostatic intermittent titration performed at low temperature $\left(\sim-15^{\circ} \mathrm{C}\right)$ showed $\mathrm{D}_{\mathrm{Li}}+$ values in the $\sim\left(10^{-15}\right.$ to $\left.10^{-13}\right) \mathrm{m}^{2} \mathrm{~s}^{-1}$ range during $\mathrm{Li}$-ion insertion and extraction (Supplementary Fig. 22). The total polarization potential, time dependent change in $\mathrm{OCV}$ at various states of charge performed at $\sim-15^{\circ} \mathrm{C}$ and corresponding reaction resistance plots are included in Supplementary Fig. 23.

Mechanical strength of the electrode. Static uniaxial tensile tests were conducted to quantify the strength and strain-to-failure for the freestanding composite papers by use of a custom-built setup. Figure $3 a$ shows a schematic of the test setup, in which the load cell is attached to a digital meter, connected to a transducer electronic data sheet in order to transfer the data to host computer through an RS232 serial port using a program written in MATLAB. Engineering stress-strain plots and tensile modulus, derived from load-displacement curves for various paper electrodes are compared in Fig. 3b,c, respectively. The rGO sample showed average tensile strength of $\sim 10.7 \mathrm{MPa}$ at a failure strain of $2.8 \%$, while $60 \mathrm{SiOC}$ sample had tensile strength of $\sim 2.7 \mathrm{MPa}$ at a strain of $1.1 \%$. Low tensile strength of the $60 \mathrm{SiOC}$ specimen was expected considering that it contained only $\sim 20 \%$ rGO. Overall, strength and modulus for these crumpled composite papers was lower than GO and rGO papers prepared from techniques other than high temperature reduction ${ }^{53,54}$. However, the strain-to-failure was almost 5 to 10 times higher than a typical GO, rGO or rGO-composite paper, suggesting that crumpled composite papers may be able to sustain larger volume changes. Surface analysis using SEM of rGO (Fig. 3d) showed occurrence of micro features after tensile test, which we suggest, are due to 
a

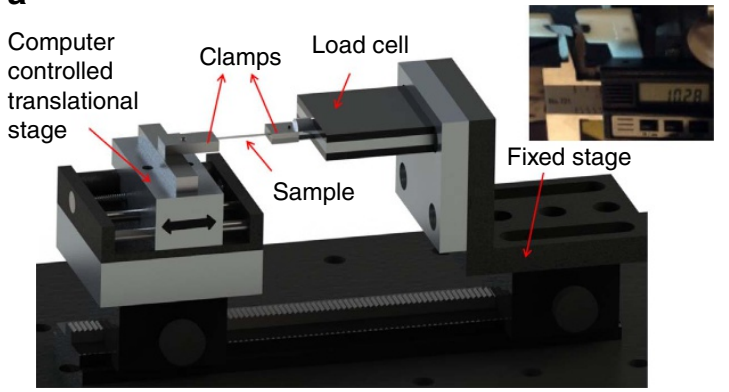

b

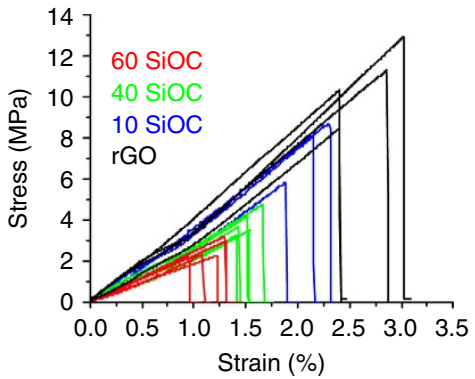

C

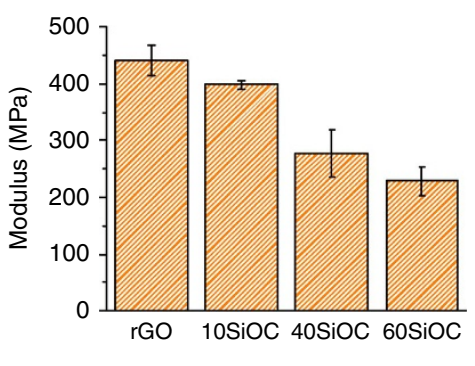

d

Before

After
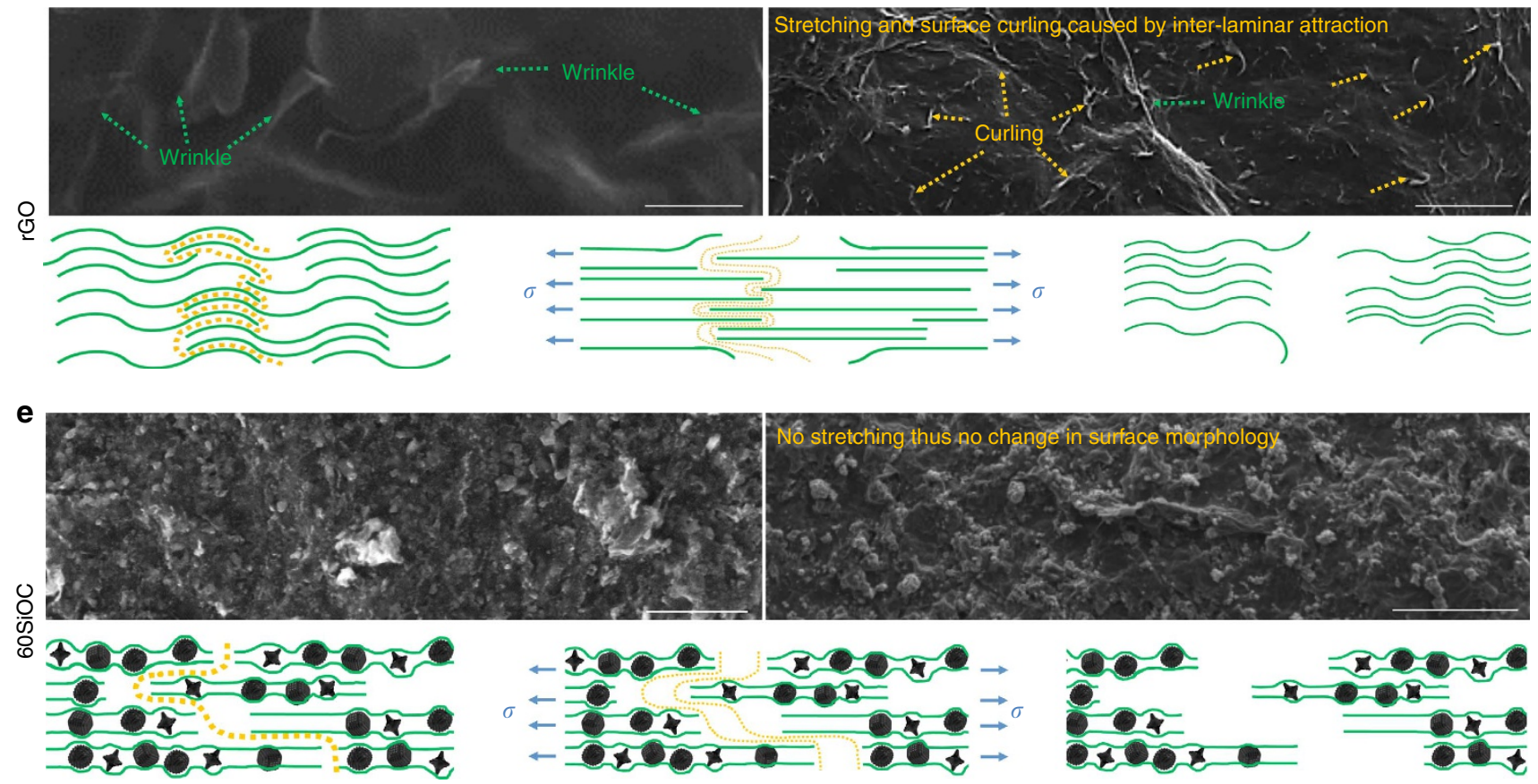

Figure 3 | Mechanical testing data. (a) Schematic of the tensile testing setup with a photograph of rGO paper immediately after the fracture. Scale reading in the photograph indicate the change in length to be $\sim 0.28 \mathrm{~mm}$. (b) Engineering stress versus strain plots of various freestanding papers derived from load versus displacement data, and (c) their corresponding modulus values. Error bars are 26.8, 7.6, 41.5, 24.1 MPa for rGO, 10SiOC, 40SiOC, and 60SiOC, respectively. The SEM images and schematic illustration to show the predicted mechanism of fracture in rGO and 60SiOC freestanding papers: (d) The rGO paper experienced stretching and rearrangement of graphene sheets before failure. (e) For 60SiOC paper, negligible stretching or rearrangement occurred. Fracture line follows SiOC particles embedded in $r G O$ flakes, resulting in gradual separation/tearing of the paper. The scale bar is $20 \mu \mathrm{m}$ in all images. Tensile test videos are included as Supplementary Movies 1 and 2.

rearrangement of rGO sheets under tensile load. These micro features are assumed to be due to curling of individual graphene sheets on the top surface when they lose contact with the sheets below them. However, for $60 \mathrm{SiOC}$ in Fig. 3e, ceramic particles acted as the point of fracture and caused rGO sheets to separate without stretching, as proven by SEM images that show no distinguishable changes before and after tensile test. Supplementary Fig. $24 \mathrm{a}-\mathrm{h}$ are the top and cross-sectional view SEM images of fractured surface. The rGO because of higher elasticity had an irregular crumpled appearance, but composite papers were more brittle and had sharper cross-section. Mode of fracture in $\mathrm{rGO}$ and $60 \mathrm{SiOC}$ papers differed significantly, as presented in Supplementary Movies 1 and 2. A loud distinct sound indicated almost instantaneous fracture of the rGO specimen, accompanied by curling of both ends of the fractured paper. Fracture of 60SiOC specimen was similar to a thin plate with an edge crack, the crack propagation could be clearly observed. In addition, stress lines could be observed only in the rGO specimen, radiating from one clamp to another and indicating distribution of stress throughout the length of the specimen. These observations are explained with the help of a schematic in Fig. 3d,e. Ex situ Raman analysis (Supplementary Fig. 25) from the top surface of the specimens before and after tests showed increase in average intensity ratio of the $I_{d}$ and $I_{g}$ peaks for rGO (0.88 versus 1.02) while the ratio was largely unaffected for composite specimen.

\section{Discussion}

Electrochemical characterization shows that $60 \mathrm{SiOC}$ is best long-term cycling electrode with reversible capacities of $\sim 702 \mathrm{mAhg}^{-1}$ electrode at 1 st cycle and $\sim 588 \mathrm{mAhg}^{-1}$ electrode at 1,020 th cycle, respectively. Although $80 \mathrm{SiOC}$ offers highest first reversible capacity of $\sim 762 \mathrm{mAhg}^{-1}$ electrode, it undergoes capacity fading and mechanical damage after few initial cycles at high currents. Hence, the capacity and cycling stability are affected by the relative amounts of SiOC and graphene in the composite, respectively. We ascribe the superior electrochemical performance of 60SiOC electrode to remarkable physical and chemical properties of its constituents and the unique 
morphological features of the paper. Because graphene sheets in $60 \mathrm{SiOC}$ occupy larger volume in the composite, well-dispersed GO sheets during the layer - by - layer filtration process arrange themselves around the SiOC particles to form a flexible composite paper. TEM (Supplementary Fig. 6), SEM (Supplementary Fig. 7) and FIB (Supplementary Fig. 8) characterization shows that morphology of the composite paper is planar and porous. The porous design therefore facilitated liquid electrolyte to reach the very interior of the electrode thereby providing easy path for solvated ions to be transported on to the surface of SiOC particles. Further, rGO because of its high electrical conductivity and mechanical flexibility provided an electrically conducting (see Supplementary Table 5) and mechanically robust (see Fig. 3b) matrix for the Li-active SiOC particles thereby buffering volume changes in the electrode and maintaining inter particle connection during long-term cycling. Microscopy (Fig. 2b, Supplementary Fig. 17) and Raman spectroscopy (Supplementary Fig. 18) of the disassembled cell reveal formation of stable SEI on a completely integral electrode, which could explain the high cycling efficiency observed in these composites.

We attribute high reversible capacity of molecular precursor derived SiOC to its amorphous structure, which is comprised of silica domains, $-s p^{2}$ carbon chains (or the free carbon phase), nano-voids and silicon/carbon open bonds (Fig. 2f and Supplementary Fig. 4 for proposed SiOC structure), that offer large number of sites, in which Li-ion can be reversibly stored. We notice that even the composite electrodes are not free from charge-discharge voltage hysteresis (or energy inefficiency) that is generally observed in precursor derived ceramics during the extraction half ${ }^{46,49,50}$. Lowering hydrogen content ${ }^{60}$ and doping of silica domains (such as B) in SiOC could be a useful strategy for improving electrical properties and lowering of voltage hysteresis in these ceramics ${ }^{40,46}$. Another important area for future investigation could be to tailor the rGO flakes for residual oxygen and hydrogen surface groups and edge defects so that lithium irreversibility and voltage hysteresis ${ }^{60}$ that arises from active defect sites could be minimized without compromising Li-ions' mobility and access to the SiOC particles ${ }^{4}$.

In summary we have demonstrated fabrication of a freestanding multi-component composite paper consisting of SiOC glass-ceramic particles supported in rGO matrix as a stable and durable battery electrode. The porous 3-D rGO matrix served as an effective current collector and electron conductor with a stable chemical and mechanical structure while, embedded amorphous SiOC particles actively cycled Li-ions with high efficiency. Elimination of inactive ingredients such as metal current collector, non-conducting polymeric binder and conducting agent reduces the total electrode weight and provides the means to produce highly efficient lightweight batteries.

\section{Methods}

Preparation of polymer derived SiOC ceramic. SiOC was prepared through the polymer pyrolysis route ${ }^{41}$, liquid 1,3,5,7-tetramethyl-1,3,5,7-tetravinylcyclotetrasiloxane (TTCS, Gelest, PA) precursor (with $1 \mathrm{wt} \%$ dicumyl peroxide added as the cross-linking agent) was cross-linked at $380^{\circ} \mathrm{C}$ in argon for $5 \mathrm{~h}$, which resulted in a white infusible mass. The infusible polymer was ball-milled in to fine powder and pyrolyzed at $1,000{ }^{\circ} \mathrm{C}$ for $10 \mathrm{~h}$ in flowing argon resulting in a fine black SiOC ceramic powder.
}

Chemicals. Sodium nitrate (99.2\%), potassium permanganate (99.4\%), sulfuric acid $(96.4 \%)$, hydrogen peroxide (31.3\% solution in water), hydrochloric acid (30\% solution in water) and methanol (99.9\%) were purchased from Fisher Scientific. All materials were used as received without further purification.

Preparation of GO and SiOC composite paper. Modified Hummer's method was used to make $\mathrm{GO}^{51}$. A total of, $20 \mathrm{ml}$ colloidal suspension of GO in 1:1 (v/v) water and isopropanol was made by sonication. Varying weight percentages of SiOC particles (with respect to GO) were added to the solution and the solution was sonicated for $1 \mathrm{~h}$ and stirred for $\sim 6 \mathrm{~h}$ for homogenous mixing. The composite suspension was then filtered by vacuum filtration through a $10 \mu \mathrm{m}$ filter membrane (HPLC grade, Millipore). The GO/SiOC composite paper obtained was carefully removed from the filter paper, dried, and thermally reduced at $500{ }^{\circ} \mathrm{C}$ under argon atmosphere for $2 \mathrm{~h}$. The large-area paper with 60SiOC composition (with an $\sim 6.25$ inch diameter, cut into rectangular strip) was similarly prepared by use of a Büchner funnel with a polypropylene filter paper (Celgard). The heat-treated paper was then punched (cut) into small circles and used as working electrode material for Li-ion battery half-cells.

Coin cell assembly and electrochemical measurements. Li-ion battery coin cells were assembled in an argon-filled glove box. $1 \mathrm{M} \mathrm{LiPF}_{6}$ (Alfa Aesar) in (1:1 v/v) dimethyl carbonate:ethylene carbonate (ionic conductivity $10.7 \mathrm{mS} \mathrm{cm}^{-1}$ ) was used as the electrolyte. A $25 \mu \mathrm{m}$ thick (19 mm diameter) glass separator soaked in electrolyte was placed between the working electrode and pure Li foil (14.3 mm diameter, $75 \mu \mathrm{m}$ thick) as the counter electrode. Washer, spring, and a top casing were placed to complete the assembly before crimping.

Electrochemical performance of the assembled coin cells was tested using a multichannel BT2000 Arbin test unit sweeping between $2.5 \mathrm{~V}$ to $10 \mathrm{mV}$ versus $\mathrm{Li} / \mathrm{Li}^{+}$that followed a cycle schedule: (a) Asymmteric mode: Li was inserted at $100 \mathrm{~mA} \mathrm{~g}^{-1}$ electrode, while the extraction was performed at increasing current densities of $100,200,400,800,1,600$ and $2,400 \mathrm{~mA} \mathrm{~g}^{-1}$ electrode for 5 cycles each, and returned to $100 \mathrm{mAg}^{-1}$ electrode for the next 10 cycles. (b) Symmetric mode: later, all the cells were subjected to symmetric cycling at a current density of $1,600 \mathrm{~mA} \mathrm{~g}^{-1}$ electrode for up to 1,000 cycles, returning to $100 \mathrm{~mA} \mathrm{~g}^{-1}$ electrode for the last 20 cycles.

Instrumentation and characterization. SEM of SiOC powder was carried out on a Carl Zeiss EVO MA10 system with incident voltage of 5-30 kV. TEM images were digitally acquired by use of a Phillips CM100 operated at $100 \mathrm{kV}$. TEM elemental mapping was performed by using a $200 \mathrm{kV}$ S/TEM system (FEI Osiris) equipped with chemiSTEM technology, a high angle annular dark field (HAADF) and Super-X windowless EDX detector. Super-X windowless EDX detector system with silicon drift detector technology allowed fast EDX data collection (a factor of more than 50 enhancement in acquisition speed of EDX chemical mapping) and large field of view elemental mapping. Acceleration voltage was $200 \mathrm{kV}$ and acquisition time was $10 \mathrm{~min}$.

A FIB system (FEI Versa 3D Dual Beam) was used for milling and imaging cross-section of the paper electrodes following standard procedures. Briefly, a platinum protective layer $(\sim 25 \mu \mathrm{m} \times 10 \mu \mathrm{m} \times 5 \mu \mathrm{m}$ in $\mathrm{x}$, $\mathrm{y}$ and $\mathrm{z}$ axes, respectively) was first deposited at an ion beam current of $\sim 5 \mathrm{nA}$. Milling was then performed using regular cross section at an ion beam current of $\sim 65 \mathrm{nA}$ to create trenches on either side and bottom face of platinum-coated area. Followed by cleaning cross-section feature $(\sim 20 \mu \mathrm{m} \times 1 \mu \mathrm{m} \times 6 \mu \mathrm{m}$ in $\mathrm{x}, \mathrm{y}$ and $\mathrm{z}$ axes, respectively) to fine mill contamination at the bottom face of platinum coated area. The acceleration voltage of $\mathrm{Ga}^{+}$was $30 \mathrm{kV}$. An ion-beam current of $\sim 40 \mathrm{pA}$ was used for imaging purposes. In-column detector for secondary electrons in beam deceleration mode was used for SEM imaging of the milled cross-section. Elemental mapping (EDS) was performed by use of an inbuilt energy dispersive spectroscopy silicon drift detector (Oxford Instruments).

Raman spectra were collected using a confocal Raman imaging system (Horiba Jobin Yvon LabRam ARAMIS) with $633 \mathrm{~nm}$ HeNe laser (laser power of $17 \mathrm{~mW}$ ) as the light source with a $\times 100$ microscope objective. Data acquisition was performed at an exposure time of $20 \mathrm{~s}$ with at least four accumulations at each point. D1 filter (10\% transparency) was employed for the ceramic powder samples. Additional material characterization was made using XRD operating at room temperature, with nickel-filtered $\mathrm{CuK} \alpha$ radiation $(\lambda=1.5418 \AA)$. The surface chemical composition was studied by XPS (PHI Quantera SXM-03 Scanning XPS Microprobe) using monochromatic $\mathrm{Al} \mathrm{K} \alpha$ radiation. For XPS depth profiling, sputtering was performed with a $5 \mathrm{keV}$ Argon ion gun for $20 \mathrm{~min}$ followed by survey scan. The sputtered area was set to $\sim 2 \mathrm{~mm} \times 2 \mathrm{~mm}$. The process was repeated four times with total sputtering time reaching $80 \mathrm{~min}$.

Further, bulk elemental composition of the pyrolyzed SiOC ceramic was measured following procedures similar to as described in the literature ${ }^{46}$. Analysis was done for carbon, oxygen and hydrogen content. Silicon content was calculated as a difference to $100 \%$. The carbon content was measured by use of LECO Analyzer Model CS844 (LECO Corp. Analytical Bus, St Joseph, MI) by the combustion method and IR detection. Approximately $50 \mathrm{mg}$ of SiOC powder mixed with accelerants as Iron chips and Lecocel II HP was used for this test. The oxygen and hydrogen contents were measured by use of LECO Analyzer Model No. ONH-836 (LECO Corp. Analytical Bus, St Joseph, MI) based on inert gas fusion thermal conductivity/infrared detection method. Specimen preparation involved mixing $\sim 34 \mathrm{mg}$ of SiOC ceramic powder with graphite powder (LECO Corp.) as an accelerant in a nickel capsule (LECO Corp.) followed by placement in graphite crucible. The crucible was then heated to $\sim 3,000^{\circ} \mathrm{C}$ in the chamber and gaseous products transferred to IR/thermal conductivity detectors for analysis. The mass per cent of carbon and oxygen were quantified in reference to the IR spectrum generated from graphite and tungsten oxide powders, respectively. 
Hydrogen content in SiOC ceramic was also confirmed by use of another equipment based on combustion/thermal conductivity detector method, CE-440 Elemental Analyser (Exeter Analytical, UK). Combustion of the weighed sample $(1.8056 \mathrm{mg}$ of fine powder) was carried out in the instrument chamber in pure oxygen under static conditions. Helium carried the combustion products through the analytical system to atmosphere. Between the thermal conductivity cells absorption trap removed water from the sample gas. The differential signal read before and after the trap reflected the water concentration and, therefore, the amount of hydrogen in the original sample. The hydrogen content by this method was observed to be $0.25 \mathrm{wt} \%$ with an error of $0.06 \%$. TGA was performed using Shimadzu $50 \mathrm{TGA}$ (limited to $800^{\circ} \mathrm{C}$ ). Samples weighing, $\sim 2.5 \mathrm{mg}$, were heated in a platinum pan at a rate of $10^{\circ} \mathrm{C} \mathrm{min}^{-1}$ in air flowing at $20 \mathrm{ml} \mathrm{min}^{-1}$. Electrical conductivity measurements were carried out by use of a four-point probe setup and Keithley 2636A (Cleveland, OH) dual channel sourcemeter in the Ohmic region. Electrochemical cycling of assembled cells was carried out using multichannel Battery Test Equipment (Arbin-BT2000, Austin, TX) at atmospheric conditions.

Mechanical testing. Static uniaxial in-plane tensile tests were conducted in a custom-built test setup. One end of the setup was connected to a $1 \mathrm{~N}$ load cell (ULC-1N Interface) and the other end was clamped to a computer-controlled translation stage (M-111.2DG from PI). The entire setup was located on a bench with self-adjusting feet. All tensile tests were conducted in controlled strain rate mode with a strain rate of $0.2 \% \mathrm{~min}^{-1}$. Paper electrodes were cut (punched out) into rectangular strips of $\sim 5 \times 15 \mathrm{~mm}^{2}$ for testing without any further modification.

\section{References}

1. Xiong, P. et al. Chemically integrated two-dimensional hybrid zinc manganate/ graphene nanosheets with enhanced lithium storage capability. ACS Nano 8, 8610-8616 (2014).

2. Ko, M., Chae, S., Jeong, S., Oh, P. \& Cho, J. Elastic a-silicon nanoparticle backboned graphene hybrid as a self-compacting anode for high-rate lithium ion batteries. ACS Nano 8, 8591-8599 (2014).

3. David, L., Bhandavat, R., Barrera, U. \& Singh, G. Polymer-derived ceramic functionalized $\mathrm{MoS}_{2}$ composite paper as a stable lithium-ion battery electrode. Sci. Rep 5, 9792 (2015).

4. Raccichini, R., Varzi, A., Passerini, S. \& Scrosati, B. The role of graphene for electrochemical energy storage. Nat. Mater. 14, 271-279 (2015).

5. Bhandavat, R., David, L. \& Singh, G. Synthesis of surface-functionalized $\mathrm{WS}_{2}$ nanosheets and performance as Li-ion battery anodes. J. Phys. Chem. Lett. 3, 1523-1530 (2012).

6. Manthiram, A. Materials challenges and opportunities of lithium ion batteries. J. Phys. Chem. Lett. 2, 176-184 (2011).

7. Cui, L.-F., Hu, L., Choi, J. W. \& Cui, Y. Light-weight free-standing carbon nanotube-silicon films for anodes of lithium ion batteries. ACS Nano 4, 3671-3678 (2010).

8. Luo, J. Y. et al. Crumpled graphene-encapsulated Si nanoparticles for lithium ion battery anodes. J. Phys. Chem. Lett. 3, 1824-1829 (2012).

9. Liu, N. et al. A pomegranate-inspired nanoscale design for large-volumechange lithium battery anodes. Nat. Nanotechnol 9, 187-192 (2014).

10. Hwang, T. H., Lee, Y. M., Kong, B. S., Seo, J. S. \& Choi, J. W. Electrospun core-shell fibers for robust silicon nanoparticle-based lithium ion battery anodes. Nano Lett. 12, 802-807 (2012).

11. Pan, L. et al. Facile synthesis of yolk-shell structured Si-C nanocomposites as anodes for lithium-ion batteries. Chem. Commun. 50, 5878-5880 (2014).

12. Cui, L. F., Yang, Y., Hsu, C. M. \& Cui, Y. Carbon-silicon core-shell nanowires as high capacity electrode for lithium ion batteries. Nano Lett. 9, 3370-3374 (2009).

13. Hertzberg, B., Alexeev, A. \& Yushin, G. Deformations in Si-Li anodes upon electrochemical alloying in nano-confined space. J. Am. Chem. Soc. 132, 8548-8549 (2010).

14. Wang, B. et al. Adaptable silicon-carbon nanocables sandwiched between reduced graphene oxide sheets as lithium ion battery anodes. ACS Nano 7 , 1437-1445 (2013).

15. $\mathrm{Hu}, \mathrm{T}$. et al. Flexible free-standing graphene- $\mathrm{TiO}_{2}$ hybrid paper for use as lithium ion battery anode materials. Carbon 51, 322-326 (2013).

16. Liang, J., Zhao, Y., Guo, L. \& Li, L. Flexible free-standing graphene/ $\mathrm{SnO}_{2}$ nanocomposites paper for Li-ion battery. ACS Appl. Mater. Interfaces 4, 5742-5748 (2012).

17. Jia, X. et al. Building robust architectures of carbon and metal oxide nanocrystals toward high-performance anodes for lithium-ion batteries. ACS Nano 6, 9911-9919 (2012).

18. Noerochim, L., Wang, J. Z., Chou, S. L., Wexler, D. \& Liu, H. K. Free-standing single-walled carbon nanotube/ $\mathrm{SnO}_{2}$ anode paper for flexible lithium-ion batteries. Carbon 50, 1289-1297 (2012).

19. Chockla, A. M. et al. Electrochemical lithiation of graphene-supported silicon and germanium for rechargeable batteries. J. Phys. Chem. C 116, 11917-11923 (2012).
20. Yue, L., Zhong, H. \& Zhang, L. Enhanced reversible lithium storage in a nanoSi/MWCNT free-standing paper electrode prepared by a simple filtration and post sintering process. Electrochim. Acta 76, 326-332 (2012).

21. Chen, Z. et al. In situ generation of few-layer graphene coatings on $\mathrm{SnO}_{2}-\mathrm{SiC}$ core-shell nanoparticles for high-performance lithium-ion storage. Adv. Eng. Mater. 2, 95-102 (2012).

22. Ji, L. et al. Graphene/Si multilayer structure anodes for advanced half and full lithium-ion cells. Nano Energy 1, 164-171 (2012).

23. Zhang, B., Zheng, Q. B., Huang, Z. D., Oh, S. W. \& Kim, J. K. SnO $\mathrm{S}_{2}$-graphenecarbon nanotube mixture for anode material with improved rate capacities. Carbon 49, 4524-4534 (2011).

24. Ji, L. et al. $\mathrm{Fe}_{3} \mathrm{O}_{4}$ Nanoparticle-integrated graphene sheets for highperformance half and full lithium ion cells. Phys. Chem. Chem. Phys. 13, 7170-7177 (2011).

25. $\mathrm{Yu}$, A. et al. Free-standing layer-by-layer hybrid thin film of graphene- $\mathrm{MnO}_{2}$ nanotube as anode for lithium ion batteries. J. Phys. Chem. Lett. 2, 1855-1860 (2011).

26. Xiao, J. et al. Electrochemically induced high capacity displacement reaction of $\mathrm{PEO} / \mathrm{MoS}_{2} /$ graphene nanocomposites with lithium. Adv. Funct. Mater. 21, 2840-2846 (2011).

27. Lee, J. K., Smith, K. B., Hayner, C. M. \& Kung, H. H. Silicon nanoparticlesgraphene paper composites for Li ion battery anodes. Chem. Commun. 46, 2025-2027 (2010).

28. Wang, $\mathrm{H}$. et al. $\mathrm{Mn}_{3} \mathrm{O}_{4}-$ graphene hybrid as a high-capacity anode material for lithium ion batteries. J. Am. Chem. Soc. 132, 13978-13980 (2010).

29. Wu, Z. S. et al. Graphene anchored with $\mathrm{Co}_{3} \mathrm{O}_{4}$ nanoparticles as anode of lithium ion batteries with enhanced reversible capacity and cyclic performance. ACS Nano 4, 3187-3194 (2010).

30. Yang, S., Feng, X., Ivanovici, S. \& Müllen, K. Fabrication of grapheneencapsulated oxide nanoparticles: Towards high-performance anode materials for lithium storage. Angew. Chem. Int. Ed. 49, 8408-8411 (2010).

31. Wang, D. et al. Ternary self-assembly of ordered metal oxide - graphene nanocomposites for electrochemical energy storage. ACS Nano 4, 1587-1595 (2010).

32. Wang, J. Z., Zhong, C., Chou, S. L. \& Liu, H. K. Flexible free-standing graphene-silicon composite film for lithium-ion batteries. Electrochem. Commun. 12, 1467-1470 (2010).

33. Zhou, G. et al. Graphene-wrapped $\mathrm{Fe}_{3} \mathrm{O}_{4}$ anode material with improved reversible capacity and cyclic stability for lithium ion batteries. Chem. Mater. 22, 5306-5313 (2010).

34. Wang, D. et al. Self-assembled $\mathrm{TiO}_{2}$-graphene hybrid nanostructures for enhanced Li-ion insertion. ACS Nano 3, 907-914 (2009).

35. Paek, S. M., Yoo, E. \& Honma, I. Enhanced cyclic performance and lithium storage capacity of $\mathrm{SnO}_{2}$ /graphene nanoporous electrodes with threedimensionally delaminated flexible structure. Nano Lett. 9, 72-75 (2008).

36. Kumar, A. et al. Direct synthesis of lithium-intercalated graphene for electrochemical energy storage application. ACS Nano 5, 4345-4349 (2011).

37. Li, X. et al. Superior cycle stability of nitrogen-doped graphene nanosheets as anodes for lithium ion batteries. Electrochem. Commun. 13, 822-825 (2011).

38. Zhao, X., Hayner, C. M., Kung, M. C. \& Kung, H. H. Flexible holey graphene paper electrodes with enhanced rate capability for energy storage applications. ACS Nano 5, 8739-8749 (2011).

39. David, L. \& Singh, G. Reduced graphene oxide paper electrode: opposing effect of thermal annealing on Li and Na cyclability. J. Phys. Chem. C 118, 28401-28408 (2014).

40. Bhandavat, R. \& Singh, G. Improved electrochemical capacity of precursorderived $\mathrm{Si}(\mathrm{B}) \mathrm{CN}$-carbon nanotube composite as Li-ion battery anode. ACS Appl. Mater. Interfaces 4, 5092-5097 (2012).

41. Bhandavat, R. \& Singh, G. Stable and efficient Li-ion battery anodes prepared from polymer-derived silicon oxycarbide-carbon nanotube shell/core composites. J. Phys. Chem. C 117, 11899-11905 (2013).

42. Saha, A., Raj, R. \& Williamson, D. L. A model for the nanodomains in polymer-derived SiCO. J. Am. Ceram. Soc. 89, 2188-2195 (2006).

43. Sanchez-Jimenez, P. E. \& Raj, R. Lithium insertion in polymer-derived silicon oxycarbide ceramics. J. Am. Ceram. Soc. 93, 1127-1135 (2010).

44. Kaspar, J., Graczyk-Zajac, M. \& Riedel, R. Determination of the chemical diffusion coefficient of Li-ions in carbon-rich silicon oxycarbide anodes by electro-analytical methods. Electrochim. Acta 115, 665-670 (2014).

45. Konno, H. et al. Si-C-O glass-like compound/exfoliated graphite composites for negative electrode of lithium ion battery. Carbon 45, 477-483 (2007).

46. Ahn, D. \& Raj, R. Cyclic stability and C-rate performance of amorphous silicon and carbon based anodes for electrochemical storage of lithium. J. Power Sources 196, 2179-2186 (2011).

47. Ahn, D., Lee, M. \& Shah, S. R. (2009). U.S. Patent Application 12/483,631.

48. Feng, Y., Feng, N., Wei, Y. \& Bai, Y. Preparation and improved electrochemical performance of $\mathrm{SiCN}$-graphene composite derived from poly(silylcarbondiimide) as Li-ion battery anode. J. Mater. Chem. A 2, 4168-4177 (2014). 
49. Graczyk-Zajac, M., Fasel, C. \& Riedel, R. Polymer-derived-SiCN ceramic/ graphite composite as anode material with enhanced rate capability for lithium ion batteries. J. Power Sources 196, 6412-6418 (2011).

50. Xing, W., Wilson, A. M., Eguchi, K., Zank, G. \& Dahn, J. R. Pyrolyzed polysiloxanes for use as anode materials in lithium- ion batteries. J. Electrochem. Soc. 144, 2410-2416 (1997).

51. Marcano, D. C. et al. Improved synthesis of graphene oxide. ACS Nano 4, 4806-4814 (2010).

52. Sadezky, A., Muckenhuber, H., Grothe, H., Niessner, R. \& Poschl, U. Raman micro spectroscopy of soot and related carbonaceous materials: Spectral analysis and structural information. Carbon 43, 1731-1742 (2005).

53. Compton, O. C., Dikin, D. A., Putz, K. W., Brinson, L. C. \& Nguyen, S. T. Electrically conductive "alkylated" graphene paper via chemical reduction of amine-functionalized graphene oxide paper. Adv. Mater. 22, 892-896 (2010).

54. Compton, O. C. \& Nguyen, S. T. Graphene oxide, highly reduced graphene oxide, and graphene: versatile building blocks for carbon-based materials. Small 6, 711-723 (2010)

55. Park, S. et al. Aqueous suspension and characterization of chemically modified graphene sheets. Chem. Mater. 20, 6592-6594 (2008).

56. Park, S. et al. Colloidal suspensions of highly reduced graphene oxide in a wide variety of organic solvents. Nano Lett. 9, 1593-1597 (2009).

57. Ganguly, A., Sharma, S., Papakonstantinou, P. \& Hamilton, J. Probing the thermal deoxygenation of graphene oxide using high-resolution in situ X-ray-based spectroscopies. J. Phys. Chem. C 115, 17009-17019 (2011).

58. Haubner, K. et al. The route to functional graphene oxide. ChemPhysChem 11, 2131-2139 (2010)

59. Park, S. et al. Hydrazine-reduction of graphite- and graphene oxide. Carbon 49, 3019-3023 (2011).

60. Zheng, T., McKinnon, W. R. \& Dahn, J. R. Hysteresis during lithium insertion in hydrogen-containing carbons. J. Electrochem. Soc. 143, 2137-2145 (1996).

\section{Acknowledgements}

We thank Professor Rishi Raj (University of Colorado) for introducing us to the field of polymer-derived ceramics. We also thank Professor Kevin Lease, Dr Nasim Rahmani, and Dr Dan Boyle (all K-State) for access to equipment their lab. G.S. would like to thank Dr Xingzhong Li (University of Nebraska-Lincoln) and Ms. Heather Shinogle (University of Kansas) for allowing access to and training on FEI Osiris and FEI Versa 3D Dual

Beam, respectively for elemental mapping. We sincerely thank Mr Andy Flores, Mr Bruce and Ms. Mary Landis (all LECO Corporation, St Joseph, MI) for access to elemental analysis instruments on LECO Analytical Bus, Ms. Elisabeth Eves (UIUC) for analysis using CE-440 Exeter Analytical instrument and Dr Jerry Hunter (UW-Madison) and Andrew Gio (Virginia Tech) for access to XPS. Publication of this article was funded in part ( $\sim 35 \%)$ by the K-State Open Access Publishing Fund. Tasks related to synthesis of SiOC and flexible paper electrodes are supported by the United States National Science Foundation grant number NSF CBET-1335862 and NSF CAREER CMMI-1454151, respectively.

\section{Author contribution}

L.D. prepared all composite specimens, performed electrochemical testing, raman spectroscopy, low magnification TEM and mechanical testing. U.B. assisted L.D. with cell assembly. R.B. synthesized SiOC particles. G.S. conceived the idea, designed the experiments, performed elemental analysis/mapping and wrote the manuscript with inputs from L.D. All authors discussed the results and commented or revised the manuscript.

\section{Additional information}

Competing financial interests: The authors declare the following competing financial interest(s): G. S., R. B. and L. D. have filed for a provisional patent: U.S. Provisional Patent Application 61/817,626-Flexible Silicon oxycarbide Graphene Composite Electrodes for High Rate Performance Lithium-ion Batteries; Filed 30 April 2013.

Supplementary Information accompanies this paper at http://www.nature.com/ naturecommunications

Reprints and permission information is available online at http://npg.nature.com/ reprintsandpermissions/

How to cite this article: David, L. et al. Silicon oxycarbide glass-graphene composite paper electrode for long-cycle lithium-ion batteries. Nat. Commun. 7:10998 doi: 10.1038/ncomms10998 (2016)

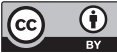

This work is licensed under a Creative Commons Attribution 4.0 International License. The images or other third party material in this article are included in the article's Creative Commons license, unless indicated otherwise in the credit line; if the material is not included under the Creative Commons license, users will need to obtain permission from the license holder to reproduce the material To view a copy of this license, visit http://creativecommons.org/licenses/by/4.0/ 